\title{
The role of identity styles and social support from peers on emotional engagement in the English as a foreign language learning
}

\begin{abstract}
Majid Al-Amri, Taibah University
This present study was designed to investigate influences of identity styles and social support from peers on emotional EFL classroom engagement in a large sample of Saudi early adolescents $(N=406)$ ranged in age from 12 to 15 . This emotional engagement construct is based on the identity styles literature and draws upon concepts of social support received from peers as one of the most important sources of validation from others during adolescence period, and as a mediating variable of the associations between students' identity styles and emotional engagement. The study shows gender differences within the sample. In general, the findings of the study demonstrate the role of social support received from peers in enhancing identity styles and influencing emotional EFL classroom engagement.
\end{abstract}

Keywords: identity styles, social support from peers, emotional EFL classroom engagement, English as a foreign language

\section{Introduction}

A growing body of research explores the direct association between foreign language identity styles (i.e., informational style, normative style, and diffuseavoidant style) and general academic performance (e.g., Berzonsky \& Kuk, 2005) or foreign language achievement (e.g., Razmjoo \& Neissi, 2010). However, scant research has examined the relationship between English as a foreign language (EFL) adolescent learners' identity styles and emotional EFL classroom engagement. Additionally, there is a lack of research addressing how social support from peers mediates identity styles and emotional engagement. Therefore, this study centres on the following research questions and expectations. First, what is the relationship between EFL students' identity styles and their emotional engagement? Second, what is the role of contextual support (i.e., social support received from peers) between adolescents' personal socio-cognitive orientation toward emotional EFL classroom engagement and EFL adolescents' identity styles?

Identity styles are different from other such individual differences as attitudes, values, and personality traits. For example, attitudes and values describe what individuals consider important, and personal traits describe what individuals are like; identity style, however, "refers to differences in the way individuals

Corresponding author's email: majid_yic@yahoo.com eISSN: $1457-9863$

Publisher: University of Jyväskylä, Language Campus (C) 2020: The authors

https://apples.journal.fi

https://doi.org/10.47862/apples.99135 
construct and revise or maintain their sense of identity" (Berzonsky, 1992, p. 771). In this regard, Berzonsky (2011) indicates that identity styles are ongoing and evolving products. Adolescents interact with their surroundings and have a certain direction and preference for a style of identity that is influenced by life events, social relationships, or interventions for the purpose of modification or change. When they enter maturity, their identity style begins to stabilize.

Berzonsky (1989) distinguishes three styles of identity: informational style, normative style, and diffuse-avoidant style. Individuals with informational identity style feel independent, open, and ready to search for information, and they listen to advice and accept instruction; individuals with normative identity style adhere to values, criteria, and standards to meet the expectations of significant others in their life; and individuals with diffuse-avoidant identity style seek pleasure, procrastinate, and avoid dealing with their interest conflicts (Berzonsky, Cieciuch, Duriez, \& Soenens, 2011). The notion of identity styles has stimulated much research, with the relationship between identity styles and learning styles, activities, and tasks being the subject of numerous conceptual and research papers. However, there has been an obvious neglect regarding investigations of the relationship between foreign language learning and adolescent identity styles. As stated by Taylor, Busse, Gagova, Marsden, and Roosken (2013):

The link between foreign language learning and adolescent identity has not inspired much research to date, although the topic warrants close scrutiny because foreign language learning occurs mostly in adolescence, usually at school, and therefore identity issues associated with learning a new language overlap with identity issues associated with adolescence (p. 4).

Emotional engagement has been used to refer to "the feelings, interests, and attitudes that students have toward learning and school" (Wara, Aloka \& Odongo, 2018, p. 108). In the present study, emotional EFL classroom engagement is used to refer to the feelings, interests, and attitudes that students have regarding learning English as a foreign language. Emotional EFL classroom engagement is of particular relevance to the learning and teaching of a foreign language: Students' previous experiences, motives for learning a foreign language, and a new learning environment may interact with each other in one emotional event inside the EFL classroom, creating different meanings for individual students and influencing their motivations (López \& Aguilar, 2013).

Of the three dimensions of engagement - behavioral, cognitive, and emotional - emotional engagement has generally received the least amount of attention from educational researchers (Sagayadevan \& Jeyaraj, 2012). This is also true within the areas of applied linguistics and EFL learning and teaching. Emotions have been significantly neglected by researchers, as their focus has been on cognition and target language use (Agudo, 2018; Garrett \& Young, 2009; Ross, 2015; Shao, Pekrun, \& Nicholson, 2019). Additionally, affect and emotion have been largely neglected in discussions of engagement in language learning, as well as in the literature of language learning and teaching, as most applied linguists and educational language specialists tend to turn to the important role of motivation in language learning (Mercer \& Dornyei, 2020). Consequently, language learning has rarely been investigated as an emotion-laden experience due to challenges to EFL students' personal identity and changes in their classroom engagement. However, there is some evidence that emotional engagement may differ 
depending on the identity style. For example, individuals with an informationoriented style reported high levels of emotional engagement, whereas those with a diffuse-avoidant identity style reported low levels of emotional engagement (Crocetti, Erentaitè, \& Žukauskienè, 2014). This study contributes to the literature of applied linguistics and EFL teaching and learning by investigating the relationship between EFL students' identity styles and emotional engagement in the classroom.

Some studies have attempted to examine the relationship between identity styles and student achievements with such mediating variables as academic autonomy (e.g., Berzonsky \& Kuk, 2000) and self-efficacy beliefs among EFL students (e.g., Hejazi, Shahraray, Farsinejad, \& Asgary, 2009). However, little is known about social support received from peers - which is considered one of the most important sources of validation from others during adolescence - as a mediating variable of the associations between students' identity styles and emotional engagement. Therefore, the present study contributes to the existing literature of applied linguistics and EFL teaching and learning by examining the role of social support received from peers in the EFL classroom as a mediating variable of the associations between EFL students' identity styles and their emotional engagement.

Within developmental systems theory (Ford \& Lerner, 1992), contextual factors play a dominant role in human development, with this role involving community from birth to death. The presence of non-parental adults plays a significant role in the lives of adolescents as they look for social support from adults outside of the family (Wang \& Holcombe, 2010). Social support received from peers "represents acceptance, approval, and esteem" (Sica, Crocetti, Ragozini, Sestito, \& Serafini, 2016, p. 187). It is a significant source of self-awareness, valuation, and appraisal of the self.

Many studies have reported a positive correlation between social support received from peers and affective engagement (e.g., Estell \& Perdue, 2013). The relationship between social support received from peers and identity styles has also been documented in the existing literature. Research has shown that there is a negative relationship between diffuse-avoidant identity style and social support received from peers. In contrast, individuals with an informational or normative identity style are more willing to socialize with peers, maintain friendships, and gather information about identity (Berzonsky \& Kuk 2000). Based on these studies on adolescence, EFL adolescent students' identity styles can be considered predictors of social support received from peers.

Research has identified differences between women and men in terms of identity styles, social support from peers, and emotional engagement. It has been reported that men score higher on diffuse-avoidance than their female counterparts (e.g., Berzonsky \& Kinney, 2008; Sica et al., 2016; Soenens, Berzonsky, Vansteenkiste, Beyers, \& Goossens, 2005). Additionally, in some investigations females have higher informational scores (e.g., Berzonsky, 2008), and in others, female students have higher normative scores (Soenens et al., 2005). Other studies have reported that female students are more emotionally engaged in classroom activities and learning tasks than male students (e.g., Amir, Saleha, Jelas, Ahmad, \& Hutkemri, 2014). In still other studies, no differences were found between males and females regarding levels of emotional engagement (e.g., Odağ, 2013). In terms of differences between males and females regarding social support from peers, women are more willing to ask for support from others and are also more pleased with the support they receive (e.g., Colarossi, 2001; Sica et al., 2016). The present 
study contributes to the literature of applied linguistics and EFL teaching and learning by investigating gender differences within the sample.

To address the research questions, based on existing literature, three hypotheses are posed. The first two hypotheses are, one, that there is a direct relationship between identity styles and emotional EFL classroom engagement and, two, that the association of identity styles with emotional EFL classroom engagement is mediated by social support from peers. The third hypothesis is based on the consideration that contextual support could determine adolescents' identity styles, enhancing or discouraging their personal socio-cognitive orientations toward emotional EFL classroom engagement: identity styles and emotional EFL classroom engagement mediate social support from peers at different levels.

\section{English education in Saudi Arabia}

The context of English education in Saudi-Arabia must be explained here. The history of teaching English in the Kingdom extends nearly eighty years, beginning in about 1940. Since then, English education has passed through different developmental stages, spanning from nearly 1950 to the present. As a lingua franca and the only official foreign language in the country, the government has exerted effort and tremendous financial support to develop instruction in English in the intermediate, secondary, and fourth, fifth, and sixth years of primary education. Recently, greater effort has been expended on student-centered learning and communicative approaches and activities; however, the results of implementing such innovative techniques have not satisfied educators' aspirations or matched the Ministry of Education's potential. The low levels of English proficiency among Saudi public-school graduates have been questioned. Although students study for nine years from primary school (from fourth grade) through high school, some high school graduates cannot conduct a short simple conversation in English. However, despite attempts to reform English education, greater efforts are still needed to overcome hindrances to innovation and creativity within the context of the current reform, the National Transformation Program 2020 (Ministry of Education), which was introduced as one of the national programs aimed at accomplishing educational objectives guided by the mandate of Saudi Vision 2030. Among its objectives are "improving the educational environment," "improving students' values and skills," "developing curricula, and methods of education and assessment," and "stimulating innovation and creativity" for educational research and teaching (Ministry of Education).

\section{Method}

\subsection{Participants}

Subjects accepted to voluntarily participate in the study were 578 adolescent students from two secondary schools in the city of Al-Madinah in Saudi Arabia. Of these, 80 participants $(13.8 \%)$ were excluded because they failed to answer three or more questions in the questionnaire, which was the primary measure of analysis for this study. Also, 92 students (15.92\%) refrained from participating in the study. Thus, the final sample was comprised of 406 participants $(70.24 \%)$ who 
ranged in age from 12 to 15 years old $(M=16.12, \mathrm{SD}=1.32)$; of these, $222(54.68 \%)$ were female and $184(45.32 \%)$ were male.

\subsection{Measures}

Three scales (i.e., emotional engagement, identity styles and social support) were combined together in one instrument. To establish trust, the questionnaire included an introduction including the purpose and significance of the study and explaining how the gathered confidential data will be used, finally expressing gratitude to participants for taking part in this study. The questionnaire was translated in the native language of the participants (Arabic). The translated questionnaire was then given to two Arabic language instructors to check the accuracy of the Arabic phrasing and to two bilingual instructors to check the accuracy of the translation overall. This back-translation procedure provided English versions identical in content with the original items of the scales. The scales were then subjected to a pilot test on a small sample of students $(\mathrm{N}=27)$. Due to the small size of the sample the pilot study was unempowered to achieve meaningful statistical analysis; however, piloting the study helped improve the statements by clarifying complex phrases and potentially unfamiliar vocabulary.

\subsection{Identity styles}

Identity Style Inventory (ISI-3) proposed by Berzonsky (1992) was used to assess identity styles. It is a 30 -item scale rated on a 5-point Likert scale ranging from 1 (not at all like me) to 5 (very much like me) that assess three identity styles (informational identity style, 11 items; normative style, 9 items; and diffuseavoidant style, 10 items). Sample items are: 'I find it's best to seek out advice from professionals (e.g., clergy, doctors, lawyers) when I have problems' (information-oriented style); 'I've more-or-less always operated according to the values with which I was brought up' (normative style); and 'When I know a situation is going to cause me stress, I try to avoid it' (diffuse-avoidant style). Using Principle Component Analysis (PCA) revealed similarity to the original observations (Berzonsky, 1992). Furthermore, Kurdek's (2002) confirmatory factor analysis (CFA) found reasonable support the hypothesized three-factor structure of identity styles. Decisions were based on Tucker-Lewis Fit Index (TLI), Root Mean Square Error Estimate (RMSEA), and Comparative Fit Index (CFI). CFA results showed that the model fits the data well. $($ RMSEA $=0.08, T L I=94, C F I=$ 92). Literature suggest that model fit is adequate when the coefficient for CFI and TLI is greater than 0.90 (Hu \& Bentler,1999), and under 0.08 for RMSEA (Kline, 1998). The reliability coefficient values of informational, formative and diffuse/avoidant identity styles were $0.76,0.68$, and 0.71 , respectively. Cronbach's Alphas were above the satisfactory level (i.e. 0.70) (Nunnally, 1978) except on the normative style subscale. However, these values correspond to those studies utilizing the inventory in languages other than English. (e.g., Berzonsky, Macek \& Nurmi 2003; Sica et al., 2016).

\subsection{Social support from peers}

Participants peer subscale of Harter's (1985) Social Support Scale (SSS). This subscale focuses on one category of people, namely peers. It measures the support 
and positive regard students feel they receive from other students in their EFL classroom. The subscale contains 6 items. For each item, students were requested to choose between two descriptions which one was more similar to them. For example, 'Some students have a close friend they can talk to about things that bother them BUT other students do not have a close friend they can talk to about things that bother them.' Then students determined whether the option was 'really true' or 'sort of true'. Thus, each statement can be rated on a 4-point scale ( $4=$ really positive; 3 = sort of positive; 2 = sort of negative; $1=$ really negative). The reliability coefficient was .88.

\subsection{Emotional engagement}

The emotional engagement index was adapted from as a sub-scale used in the literature (e.g., Wang \& Holcombe, 2010) to measure emotional engagement as one of three dimensions (behavioral, cognitive, and emotional) of school engagement. It consisted of 7 items. They represent students' sense of EFL classroom belonging and valuing of the EFL classroom. Sample items are "In general, I like the EFL classroom a lot", "I would recommend other young people to join the EFL classroom I join now", "EFL classroom is not so important for me". Responses ranged from 1 = strongly disagree through $5=$ strongly agree, with higher scores indicating greater emotional engagement. The reliability coefficient was .86.

\subsection{Procedures}

The study procedures were in accordance with the ethical guidelines for research with human participants, and were approved by the Scientific Committee at the university. The researcher visited two secondary schools in the area of AlMadinah for the purpose of collecting data from students. The purpose of the visit was to provide the principals with the aim of the study, reasons for the proposed data collection, and anonymity of information collected from research participants. Through their English language teachers, students were introduced to the study and invited to participate. They were told that their participation was voluntary, and was no compensation for their participation in the study. Those who accepted to participate in the study received a questionnaire from their English language teachers along with a letter about the study for parental consent to submit to a designated EFL teacher at school. All the parents or legal guardians provided written informed consent.

\section{Findings}

\subsection{Descriptive statistics}

Descriptive analyses (See Table 1) show that students attained mid-range points on emotional engagement $(M=3.09 ; \mathrm{SD}=0.80)$, informational identity style $(\mathrm{M}=$ 3.08 ; $\mathrm{SD}=0.53)$, and peer social support $(\mathrm{M}=3.11 ; \mathrm{SD}=0.51)$. They also achieved moderately high points on normative identity style $(\mathrm{M}=3.29$; $\mathrm{SD}=0.49)$ and moderately low scores $(\mathrm{M}=2.70 ; \mathrm{SD}=0.57)$ on diffuse/avoidant identity style. 
To estimate differences between males and females, independent samples $t$ tests were used to compare scores on all subscales (emotional engagement, identity styles and social support from peers) (See Table 2). There was a significant difference between mean scores on diffuse-avoidant identity style, and normative identity style.

Table 1. Descriptive Statistics for Males and Females on Identity Styles, Emotional Engagement, and Social Support from Peers.

\begin{tabular}{lllll}
\hline & \multicolumn{3}{c}{ Gender differences } & \\
\cline { 2 - 5 } & Males $(\mathrm{N}=184)$ & Female $(\mathrm{N}=222)$ & $\mathrm{F}$ & p value \\
\hline Emotional engagement & $3.06(.77)$ & $3.12(.82)$ & 3.06 & .06 \\
\hline Peer support & $3.05(.52)$ & $3.16(.49)$ & 12.72 & .00 \\
\hline Informational identity & $3.06(.56)$ & $3.09(.50)$ & 2.12 & .87 \\
\hline Normative identity & $3.27(.52)$ & $3.29(.46)$ & .06 & .93 \\
\hline Diffuse/avoidant identity & $2.75(.56)$ & $2.64(.58)$ & 11.92 & .00 \\
\hline
\end{tabular}

\subsection{Path analyses}

Based on what has been discussed in the literature and according to the hypotheses of the study, two structural equation models was developed (Figure $1,2)$. Model one hypotheses a direct relationship between identity styles and emotional engagement. Model two was to examine the moderation effect of the social support from peers on the relationships between identity styles and emotional engagement. Four fit indices were used for evaluating the model fit: the chi-squared test, the root mean square error of approximation (RMSEA), the normed fit index (NFI), and the comparative fit index (CFI). Literature suggest that CFI and TLI should be equal to or exceed .095, with coefficient values greater than .90 considered to be adequate (Bryne, 2001; Hu \& Bentler, 1999); The value of RMSEA for an excellent model should be less than .05 and for an adequate model should be under 0.08 (Browne \& Cudeck, 1993). The models were estimated by using the robust weighted maximum likelihood (WML) estimation approach. This analysis was carried out by Mplus Version 8.1.

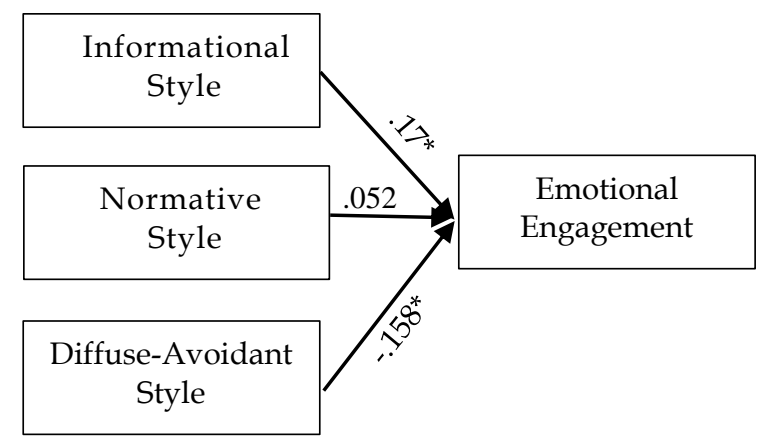

Figure 1. Path coefficients showing the direct effect of identity styles on emotional engagement. ${ }^{*} \mathrm{p}<.05$.

Figure 1 shows the hypothesized direct relationship model and path coefficients for the participants. The model showed that the normative style did not have a significant effect on emotional engagement. On the other hand, the informational and diffuse-avoidant 
styles significantly influenced emotional engagement - positively for the informational style $\left(\beta=.17^{*}, p<.05\right)$ and negatively for the diffuse-avoidant style $\left(\beta=-.158^{*}, p<.05\right)$. The Test of Independence (Pearson Chi-Square) revealed that there is no a statistical relationship between the categorical variables $(p<1.00)$. The RMSEA has the value of zero, namely, the data fit the hypothesized model.

Based on existing literature, the variable associated with the moderation effect (social support from peers) was centered. It was assumed that the direct effect of identity styles on emotional engagement could be influenced by the intervention of social support from peers as a mediating variable. Therefore, the construct of social support from peers was introduced as a mediating variable (Figure 2).

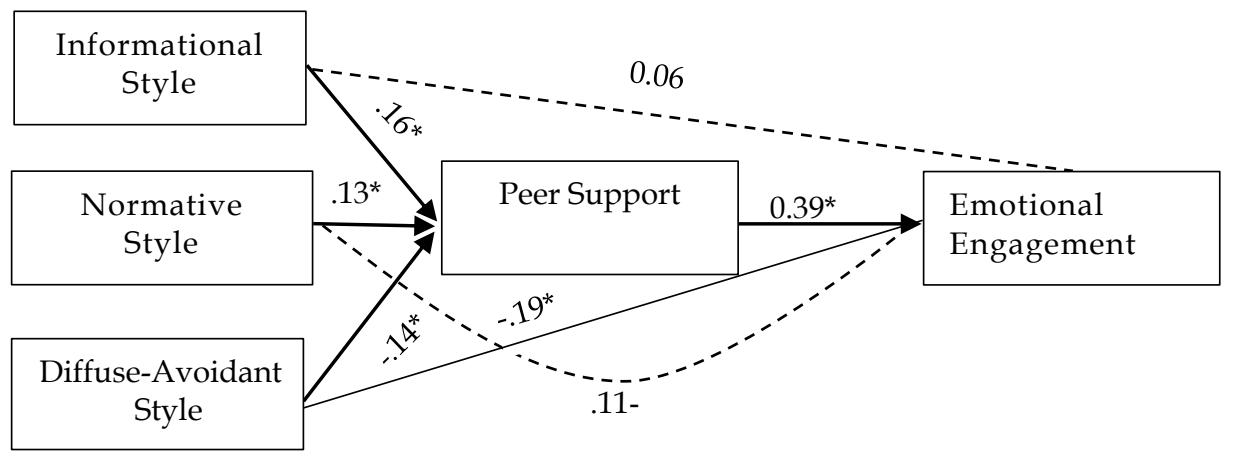

Figure 2. Full Path Model. ${ }^{*} \mathrm{p}<.05$.

The goodness-of-fit tests were used to compare the observed values to the predicted values. To an extent, low fit was observed. CFI and TLI exceeded 92, and 0.96 respectively; however, the minimum likelihood ratio test showed that the proposed model does not fit the data well. Chi-square estimate with 3 degree of freedom was statistically significant $19.87(p=.00012)$. The value of RMSEA for the model 0.115. Figure 2 shows the full model and path coefficients. There was a significant direct association between diffuse-avoidant identity style and emotional engagement. Figure 2 also shows that there was no direct association between the other two identity styles, namely informational identity and normative identity styles and emotional engagement. At this stage, the model was needed to be modified in order to improve the fit. However, the model was modified and the effect of sex was controlled on the identity styles and emotional engagement. Two binary variables were used. A " 1 " value is placed in the binary variable for female and " 0 " value for male. The reduced model fit the data well. The reduced model is illustrated in Figure 3.

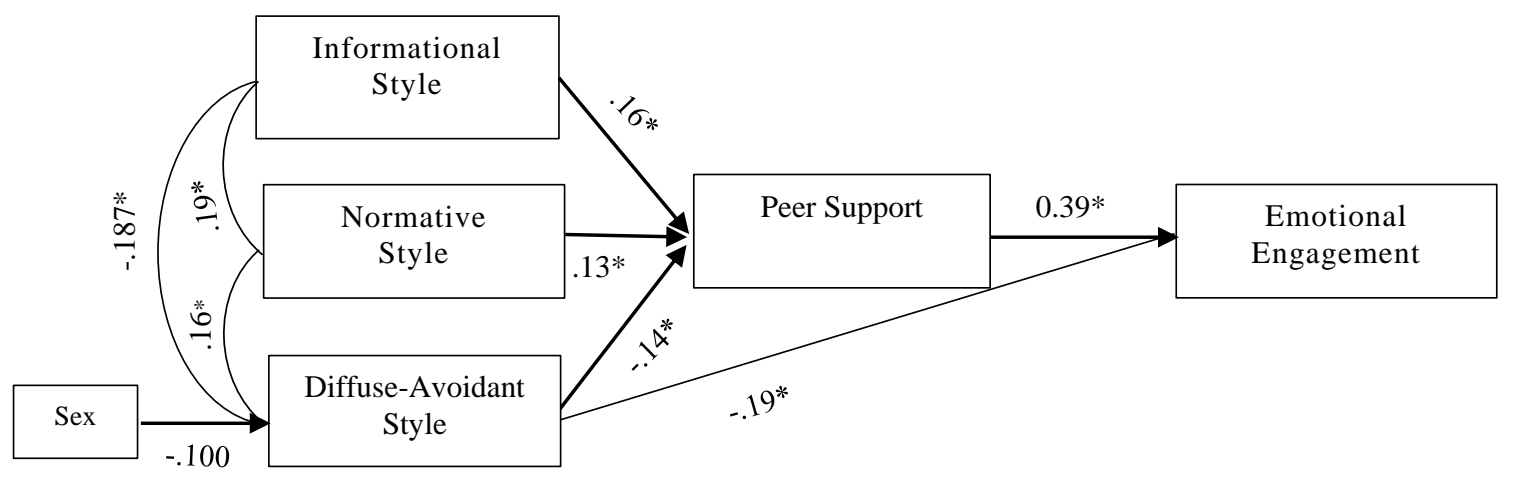

Figure 3. Reduced/Hypothesized Path Model. * $\mathrm{p}<.05$. 
As illustrated in Figure 3, there are direct and indirect significant casual relationships between diffuse/avoidant identity style and emotional engagement. There were no significant direct causal relationships between informational and normative identity styles and emotional engagement; however, their indirect causal relationships in the reduced model are statistically significant. The likelihood-ratio chi-squared test reported no statistically significant value (6.12). Goodness of other fit indices also reveals quite a good fit of the model (v2 1/4 $44: 153, \mathrm{df}=16, \mathrm{p}$ value $=0.0008 ; \mathrm{CFI}=91, \mathrm{TLI}=94 ; \mathrm{RMSEA}=0.037$ [.028-.052]). Therefore, it can be argued that social support received from peers can only be a mediator between informational and normative identity styles.

\subsection{Piloting a possible model}

Based on notions of DST it has been suggested that emotional engagement may have a causal relationship with social support from peers. Therefore, another model (not reported here) was tested whereby emotional engagement mediated associations between identity styles and social support received from peers. Comparison of the goodness-of-fit indices of the two models revealed that this possible model was not as good as the fit of the hypothesized model. The X2 value and fit indices of the resulting models showed that model fit decrease was significant.

\section{Discussion}

This present study was designed to investigate the role of identity styles and social support from peers on emotional EFL classroom engagement in a large sample of Saudi early adolescents. This emotional engagement construct is based on the identity styles literature and draws upon concepts of social support received from peers as one of the most important sources of validation from others during adolescence period, and as a mediating variable of the associations between students' identity styles and emotional engagement. The main purpose of the present study was to recognize features that could reinforce emotional engagement in early adolescents in contexts such Saudi Arabia, where English is taught as a foreign language. To achieve this purpose, the study was designed to explore the impact of identity styles and social support from peers on emotional engagement construct and have investigated the mediating influence of social support received from peers on the connection between identity styles and emotional engagement. The study shows gender differences within the sample. In general, the findings of the study demonstrate the role of social support received from peers in enhancing identity styles and influencing emotional engagement.

Generally, the findings of the current research on gender differences show that male students scored higher on diffuse-avoidance than female students. This finding is consistent with what has been reported in the literature (e.g., Sica et al., 2016; Soenens et al., 2005). According to Berzonsky and Kinney (2008) there is no clear-cut interpretation for this relationship, but the role of other factors (e.g., gender-role stereotypes, parental process) should be taken into consideration. Concerning social support, it was found perceived social support from peers is much higher for girls, compared to their male counterparts. This finding is also in line with some research findings in the literature (Colarossi, 2001; Sica et al., 2016) 
that indicated that women are more willing for social support than men and are also more pleased with the support obtained from their peers. In respect of emotional engagement, no differences were found between males and females. This finding is in line with the finding of a number of studies, such as that of Odağ (2013).

In general, the findings of the present study confirm the study hypothesis that the relationship between identity styles and emotional engagement is mediated by perceived social support from peers.

The study found that identity styles affects emotional engagement indirectly and through the mediating role of social support from peers differences in emotional engagement exist. Taking into account that such variations will be reduced, if social support from peers is eliminated, these findings indicate that social support from peers and identity styles are able to influence emotional engagement.

Based on the findings of the study, identity styles have relationships with emotional engagement at different levels. For instance, diffuse-avoidant style has a negative relationship with emotional engagement, and social support from peers. Such a finding confirms Berzonsky's (2008) argument that adolescents with a diffuse-avoidant identity style are instable. This instability affects their own abilities of using social and cognitive strategies such as peer mediated support strategies. In addition, feeling of inconsistency results in procrastination and avoiding interest and identity conflicts, values related to individuals with diffuseavoidant identity style (Berzonsky et al., 2011), which in turns affects negatively emotional engagement. It appears that individuals with a diffuse-avoidant identity style lack the capability of setting their personal and social goals and, therefore, cannot engage emotionally in the EFL context. This result justifies the view that adolescents with a diffuse-avoidant identity style are at an increased risk for emotional engagement.

It was found that there is no direct relationship between normative identity style and emotional engagement; however, it appeared that this association turned to be statistically significant, when social support from peers was considered. That is the connection between normative identity style and emotional engagement was mediated by social support from peers. This finding supports previous research in the literature indicating that, normative identity style cannot predict emotional engagement. (Crocetti, et al., 2014). This might be due to the fact that adolescents with normative identity style adhere to values, criteria, and standards to meet expectations of significant others (Berzonsky et al., 2011), which may negatively influence their engagement. In the current investigation, the sample comprised beginner learners of EFL in intermediate school. It seems that learning a foreign language creates a challenge for adolescents with normative identity. As a result, their identity styles have a negative relationship with emotional engagement. This negative relationship might be due to their inability to go beyond their previous frame of reference to internalize the new criteria and the context of the target language.

The study indicated that there is a positive correlation between normative identity style and social support received from peers, and that social support from peers plays a mediating role in the effect of adolescents' emotional engagement. As argued by Berzonsky $(1989,1992,2004,2008,2011)$, adolescents with normative identity style comply with social rules and others' expectations. The resulting feeling of the importance of social relationships might positively affect their 
perceptions of social support received from peers which bring about a difference in the emotional engagement of adolescents as a result. Therefore, when normative identity style has a relationship with social support from peers, it can anticipate emotional engagement.

One more result of the current research is the significant positive and direct impact of informational identity style on emotional engagement. This result which is in consistent with above results (Berzonsky, 1989, 1992, 2004, 2008, 2011) indicates that, due to independence, empathy, openness that transcend selfish interest (Berzonsky et al., 2011), individuals with an informational style seek social support from peers, and this tendency positively affects their emotional engagement as well. There was no direct significant correlation between informational identity and emotional engagement when social support from peers was considered. This might be attributed to the fact that an informational style related positively to social notions such as universalism and benevolence (Berzonsky et al., 2011), which in turn positively affect their social support from others as well as their emotional engagement.

The results of the investigation showed that EFL adolescent learners with an informational identity style reported high levels of emotional engagement and those with a diffuse-avoidant identity style reported low level of emotional engagement (Crocetti et al., 2014). The results also revealed that the prediction of EFL adolescent learners' behaviors with normative identity styles was more intricate than two other identity styles because their positive emotional engagement are more influenced by other factors like perceived social support from peers.

The present study also suggested that identity styles affect EFL adolescent learners' emotional engagement. These results have significant implications for EFL education as well as the social development of EFL adolescents. The study clearly shows that in interpreting (and adjusting) EFL student engagement, EFL educators should pay a special attention to notions with respect to the idea of "support from others". Among these notions, the mediating effect of social support from peers is highly considerable.

The outcome of this study shows that social support from peers can mediate the relationship between EFL students' identity styles and emotional engagement in the classroom. These findings are in agreement with the literature indicating that identity styles can be considered as predictor of social support received from peers, and higher perceived social support from peers is associated with higher emotional engagement (Berzonsky \& Kuk 2000).

This study investigates the influence of identity styles and social support from peers on adolescents' emotional engagement in the context of EFL classrooms. Future research should be conducted in the context of other foreign languages too. Further, this study did not explore the influence of age on the association between identity style, social support from peers, and emotional engagement. Therefore, future studies should investigate this aspect using qualitative research.

\section{Disclosure statement}

The author declared no conflict of interest. 


\section{References}

Agudo, J. (2018). Emotions in Second Language Teaching: Theory, Research and Teacher Education. Cham, Switzerland: Springer.

Amir, R., Saleha, A., Jelas, Z. M., Ahmad, A. R., \& Hutkemri. (2014). Students' Engagement by Age and Gender: A Cross-Sectional Study in Malaysia. Middle-East J. Sci. Res., 21(10), 1886-1892.

Berzonsky, M. D. (1989). Identity Style: Conceptualization and Measurement. Journal of Adolescent Research, 4, 268-282.

Berzonsky, M. D. (1992). Identity Style and Coping Strategies. Journal of Personality, 60, 771-788.

Berzonsky, M. D. (2004). Identity Processing Style, Self-Construction, and Personal Epistemic Assumptions: A Social-Cognitive Perspective. European Journal of Developmental Psychology, 1(4), 303-315.

Berzonsky, M. D. (2008). Identity Formation: The Role of Identity Processing Style and Cognitive Processes. Personality and Individual Differences, 44(3), 645-655.

Berzonsky, M. D. (2011). A Social-Cognitive Perspective on Identity Construction. In S. J. Schwartz, K. Luyckx, \& V. Vignoles (Eds.), Handbook of Identity Theory and Research: Structures and Processes, 55-76. London, England: Springer.

Berzonsky, M. D., Cieciuch, J., Duriez, B., \& Soenens, B. (2011). The How and What of Identity Formation: Associations Between Identity Styles and Value Orientations. Personality and Individual Differences, 50(2), 295-299.

Berzonsky, M., \& Kinney, A., (2008). Identity Processing Style and Defense Mechanisms. Polish Psychological Bulletin, 39(3), 111-117.

Berzonsky, M. D., \& Kuk, L. (2000). Identity Status, Identity Processing Style, and the Transition to University. Journal of Adolescent Research, 15 (1), 81-98.

Berzonsky, M.D., \& Kuk, L. S. (2005). Identity Style, Psychological Maturity, and Academic Performance. Personality and Individual Differences, 39(1), 235-247.

Berzonsky, M. D., Macek, P., \& Nurmi, J.-E. (2003). Interrelationships Among Identity Process, Content, and Structure: A Cross-Cultural Investigation. Journal of Adolescent Research, 18(2), 112-130.

Browne, M. W., \& Cudeck, R. (1993). Alternative Ways of Assessing Model Fit. In K. A. Bollen, \& J. S. Long (Eds.), Testing Structural Equation Models, 136-162. Newbury Park, CA: Sage.

Byrne, B. M. (2001). Structural Equation Modeling with AMOS: Basic Concepts, Applications, and Programming. Mahwah, NJ: Lawrence Erlbaum Associates.

Colarossi, L. (2001). Adolescents Gender Differences in Social Support: Structure, Functions and Provider Type. Social Work Research, 25(4), 233-241.

Crocetti, E., Erentaitè, R., \& Žukauskienè, R. (2014). Identity Styles, Positive Youth Development, and Civic Engagement in Adolescence. Journal of Youth and Adolescence, 43(11), 1818-1828.

Estell, D., \& Perdue, N. (2013). Social Support and Behavioral and Affective School Engagement: The Effects of Peers, Parents, and Teachers. Psychology in the Schools, $50(4), 325-339$.

Ford, D. H., \& Lerner, R. M. (1992). Developmental Systems Theory: An Integrative approach. Newbury Park, CA: Sage.

Garrett, P., \& Young, R. (2009). Theorizing Affect in Foreign Language Learning: An Analysis of One Learner's Responses to a Communicative-Based Portuguese course. Modern Language Journal, 93(2), 209-26.

Harter, S. (1985). Manual for the Social Support Scale for Children. Denver: University of Denver.

Hejazi, E., Shahraray, M., Farsinejad, M., \& Asgary, A. (2009). Identity Styles and Academic Achievement: Mediating Role of Academic Self-Efficacy. Social Psychology of Education: An International Journal, 12(1), 123-135.

Hu, L., \& Bentler, P. M. (1999). Cutoff Criteria for Fit Indexes in Covariance Structure Analysis: Conventional Criteria Versus New Alternatives. Structural Equation Modeling, 6(1), 1-55. 
Kurdek, L. A. (2002). On Being Insecure about the Assessment of Attachment Styles. Journal of Social and Personal Relationships, 19, 811-834.

Kline, R. B. (1998). Principles and Practice of Structural Equation Modeling. New York, NY: The Guilford Press.

López, M. G. M., \& Aguilar, A. P. (2013). Emotions as Learning Enhancers of Foreign Language Learning Motivation. Profile, 15(1), 109-124. Retrieved April 8, 2020, from https://revistas.unal.edu.co/index.php/profile/article/view/37872/40579

Mercer, S., \& Dörnyei, Z. (2020). Engaging Language Learners in Contemporary Classrooms. Cambridge: Cambridge University Press.

Ministry of Education. (n.d.). Education and Vision 2030. Retrieved April 2, 2020, from https://www.moe.gov.sa/en/Pages/vision2030.aspx

Nunnally, J. C. (1978). Psychometric Theory. New York McGraw-Hill.

Oda $\breve{g}$, Ö. (2013). Emotional Engagement During Literary Reception: Do Men and Women Differ? Cognition and Emotion, 27(5), 856-874.

Razmjoo, S. A., \& Neissi, S. (2010). Identity Processing Styles and Language Proficiency among Persian Learners of English as a Foreign Language. Psychological Reports, 107(3), 822-832.

Ross, A. S. (2015). From Motivation to Emotion: A New Chapter in Applied Linguistics research. University of Sydney Papers in TESOL, 10, 1-27. Retrieved April 16, 2020, from https://epubs.scu.edu.au/tlc_pubs/290/

Sagayadevan, V., \& Jeyaraj, S. (2012). The role of Emotional Engagement in LecturerStudent Interaction and the Impact on Academic Outcomes of Student Achievement and Learning. Journal of the Scholarship of Teaching and Learning, 12(3), 1-30. Retrieved April 22, 2020, from https://scholarworks.iu.edu/journals/index.php/josotl/article/ view $/ 2152$

Shao, K., Pekrun, R., \& Nicholson, L. J. (2019). Emotions in Classroom Language Learning: What Can We Learn from Achievement Emotion Research? System, 8, 1-11.

Sica, L. S., Crocetti, E., Ragozini, G., Sestito, L. A., \& Serafini, T. E. (2016). Future-Oriented or Present-Focused? The Role of Social Support and Identity Styles on 'Futuring' in Italian Late Adolescents and Emerging Adults. Journal of Youth Studies, 19(2), 183-203.

Soenens, B., Berzonsky, M., Vansteenkiste, M., Beyers, W., \& Goossens, L. (2005). Identity Styles and Causality Orientations: In Search of the Motivational Underpinnings of the Identity Exploration Process. European Journal of Personality, 19, 427-442.

Taylor, F., Busse, V., Gagova, L., Marsden, E., \& Roosken, B. (2013). Identity in Foreign Language Learning and Teaching: Why Listening to Our Students' and Teachers' Voices Really Matters. Retrieved May 12, 2020, from https://www.teachingenglish.org.uk/article/ identity-foreign-language-learning-teaching-why-listening-our-students $\% \mathrm{E} \% 80 \% 99$-teachers $\%$ E2\% $80 \% 99$-voices

Wang, M. T., \& Holcombe, R. (2010). Adolescents' Perceptions of School Environment, Engagement, and Academic Achievement in Middle School. American Educational Research Journal, 47, 633-662.

Wara, E., Aloka, P. J., \& Odongo, B. S. (2018). Relationship between Emotional Engagement and Academic Achievement among Kenyan Secondary School Students. Academic Journal of Interdisciplinary Studies, 7(1), 2281-3993.

Received January 10, 2020

Revision received July 24, 2020

Accepted August 19, 2020 